https://doi.org/10.48009/1_iis_2008_37-45

\title{
AN EXAMINATION OF DECISION CONFIDENCE AND ILLUSION OF CONTROL IN A GROUP SETTING
}

\author{
Sathasivam Mathiyalakan, Winston Salem State University, mathiyalakansa@wssu.edu
}

\begin{abstract}
Decision confidence is a factor in indicating the acceptance and use of a DSS. Prior research has shown the presence of both over and under confidence resulting in DSS use and both could lead to disastrous outcomes for the organization. There are very few methodologies or strategies designed to address issues related to decision confidence and user calibration a group setting. Achieving perfect calibration avoids the negative impacts on organizational performance that can occur in the presence of either over or under confidence. To address this issue, Kasper develops the theory of DSS design. Kasper emphasizes the need for empirical work and for testing of the theory. We present an incentive-based experimental approach for aiding in achieving the goal of high levels of user calibration in a business lending situation. The technique draws directly from economic literature. The technique described in this study is easy to implement and can be an additional mechanism in the DSS designer's tool bag.
\end{abstract}

Keywords: Calibration, Illusion of control, Induced value concept, DSS design, Experimental economics, Group decision making.

\section{INTRODUCTION}

Decision confidence is "One's belief in the quality of the decision" [10] and is a factor in indicating the acceptance and use of a DSS. Overconfidence can be defined as "having unmerited confidence- believing something or someone is capable when they are not" (Wikipedia). It can also be defined as "The ability to solve difficult or novel problems is often overstated" [1]. Researchers have shown that overconfidence in judgment exists ([2], [5], [11], [29]). While such massive levels of overconfidence seem unreasonable, overconfidence is perhaps the most well-established phenomenon in the behavioral sciences. When asked about many things, such as driving, a large majority of all people rate themselves as above average [13]. A long stream of experiments have found that people are overconfident in a wide variety of tasks ranging from trivial pursuit type questions to the perception of acoustical signals ([15], [20], [28]).

The existence of overconfidence has been examined in many settings. Panko [19] reports the error rate is between $2 \%$ and $5 \%$ in software development. Researchers also find that about one third of development effort goes toward post development error correction (Grady, 1995). Even with such post development efforts, errors of $0.1 \%$ to $0.4 \%$ still remain [19]. Researchers have also studied spreadsheets to determine whether the spreadsheets have errors and if so the extent of such errors. Few firms have mandates on end user application testing and individuals rarely systematically test their work [19].

Overconfidence has also been seen in decision support systems use and in database queries. Even experts in a wide variety of fields are often appallingly overconfident within their domains of expertise [9]. Overall, in both contrived and realistic tasks, there seems to be a pervasive human tendency toward overconfidence. Prior research has shown the presence of both over and under confidence resulting from the use of a DSS. Both could lead to disastrous outcomes for the organization. Overconfidence could lead to the development of lower quality decisions as the users may ignore other sources of information [6]. Overconfidence in DSS could also result in users engaging in a course of action that results in negative consequences for the organization and/or the decision maker. Under confidence in the DSS and in its support could result in lost opportunities.

Few methodologies or strategies designed to address issues related to decision over confidence and user calibration exist within DSS setting. Kasper [10] proposed a DSS design theory for user calibration. Kasper's work focuses on the issues of "calibration" and "user calibration." Kasper defines calibration as "a measure of the correspondence between the subjective decision confidence one assigns to a decision and the objective quality of that decision. Kasper goes on to coin the term "user calibration" and hypothesizes that the design of a DSS can affect decision maker (user) calibration. Achieving perfect 
calibration avoids the negative impacts on organizational performance that can occur in the presence of either over or under confidence. While Kasper's theory plays an important role in DSS calibration, we suggest that there are additional tools and techniques that are both easy to understand and implement. Our purpose here is to describe and illustrate an additional useful concept and mechanism that is easy to understand and implement for use in the DSS designer's "tool bag."

We also suggest the potential importance of an incentive-based approach for aiding in achieving the goal of high levels of user calibration. This approach draws directly from basic economics and uses both information charges and performance-based monetary rewards. Using a line of research that we have been pursuing, we offer the results of a set of experiments to illustrate the procedure. The motivation for our research stems from the observation of Morris and Marshall [18] who notes "There exists paucity of research on examining issues related to psychological (perceived) control within the IS research.” In section 2 we review relevant literature. We then describe our experimental process and present the results. We conclude with summary remarks.

\section{PRIOR RESEARCH}

Researchers such as Langer suggest that over confidence occurs due to illusion of control. Langer [14] defines illusion of control as "an expectancy of a personal success probability inappropriately higher than the objective probability would warrant" (p.62). Langer attributes this phenomenon to the need in individuals to maintain personal control. Langer found evidence to suggest that when a chance situation is similar to a skilled situation, there is a greater likelihood of the existence of illusion of control. There are many ways competition, choice, and involvement in a chance situation to introduce illusion of control within a decision making environment [14]. Morris and Marshall [18] developed a survey instrument to assess perceived control. The concept of perceived control was operationalized and found to be a as a multi dimensional construct consisting of five factors timeframe, feedback signal, feedback duration, strategy, and metaphor knowledge.

To address the issue of illusion of control and miscalibration, Kasper [10] developed a theory of DSS design. Kasper's theory of DSS design draws heavily from behavioral theories and utilizes the properties of "expressiveness, visibility, and inquirability." Kasper further argues that "the DSS design theory for user calibration asserts that the DSS symbols and actions needed for users to achieve the goal of perfect calibration are prescribed by the properties of expressiveness, visibility, and inquirability." Expressiveness refers to the tone in which dialogue symbols are presented, visibility refers to seeing the DSS and the specific problem being addressed, and inquirability refers to the extent to which the system is designed for user calibration. Kasper emphasized the need for empirical work (p. 229) and for testing of the theory (p.228). We concur with his argument about the importance of accurate user calibration. We also agree with the importance of empirical and theory testing work.

In some organizations and settings, however, it may be extremely difficult or expensive to pursue this path. As Kasper [10] emphasized in his concluding remarks, "Much empirical work remains to be done before specific recommendations can be made." Over time, empirical research can help relate organizational characteristics and settings to the effectiveness of design approaches.

Laboratory experiments have shown that illusion of control exists in situations involving the use of DSS ([3], [4], [12]). Popular spreadsheet programs such as Microsoft Excel have What-if analysis capability. What-if analysis presents a subset of DSS capabilities. Davis and Kotteman [3] conducted two experiments to determine whether the use of What-ifanalysis creates a climate for illusion of control and thereby causing the decision makers to overestimate the role and effectiveness of the DSS. The two experiments involve a production planning task. Perception of users with What-if analysis capability is compared to the users who do not have such capability, i.e. unaided decision making. The results of the first experiment indicate that that although the use of the What-if capability did not provide an advantage, the users perceived that the use of What-if capability was superior when compared to unaided decision making. In the second experiment, they find that although the use of a quantitative decision rule would have led to significant cost savings, the users were indifferent between What-if analysis and the quantitative decision rule. Davis and Kotteman [3] thereby conclude that the use of What-if analysis capability led to illusion of control and go on to state "Such misjudgments could lead people to continue using What-if analysis even when it is not beneficial and to avoid potentially superior decision support technologies." 
Davis and Kotteman [4] also assessed the use of decision rules within the production planning environment. They initially find that in the base case subjects underestimated the usefulness of a decision rule. The use of the decision rules resulted in a significantly higher performance. The researchers proceeded to provide the subjects additional information, namely feedback on their performance and an explicit statement of the benefits associated with using the decision rule. With feedback perceived usefulness of the rule, use of the decision rule, and performance all increased. Description of the rule benefits did not lead to improvement in either perceived usefulness of the rule or the performance. They argue that the use of feedback is an effective mechanism for increasing perception and performance.

Kottemann, Davis and Remus [12] conducted a between subjects experiment to determine whether the use of What-if analysis leads to the users overestimating its capability within a production planning environment. They find that the users who had What-if capability expressed high confidence even through such use led to significantly lower performance than the non users. Kottemann, Davis and Remus [12] conclude that "the present results imply that decision makers may willingly, but unknowingly, continue using What-if analysis despite lack of actual performance advantages" (p.36). The authors also highlight a need for future research in this area to test implications of their findings.

Marsden and Mathiyalakan [16] examine performance-perception relationships of users with What-if facility under conditions where there is performance based reward system and system usage costs. In their study, subjects act as commercial lending officers and use the What-if facility present within a DSS to decide on loan amounts. In their study, Marsden and Mathiyalakan use two alternative DSS system design. In the first design, which they term as the basic system, No What-if capability exists. In the second system design which they refer to as the advanced system What-if capability exists for checking the impact of a proposed loan amount on pro forma Income statement and Balance sheet. Both systems do provide information support for assessing management capability, economy, and firm credit rating. They find that no performance advantage results by using What-if facility. They also find that the subjects were able to accurately portray the support provided, a contrast to the earlier findings where subjects perceived What-if to be a useful tool even if it did not provide an advantage.
These studies indicate that in some instances, due to illusion of control the decision makers are unable to accurately portray the value of the What-if capability present within the DSS. This has a profound impact for DSS designers and the organization. The organizations may continue to provide and the decision makers continue to use DSS that does aid in performance even though the decision makers continue to believe that these DSS provide valuable support.

Issues related to decision confidence has also been examined in group setting. In one of the earlier studies in GDSS, Steeb and Johnson [27] find no difference between groups with and without GDSS in terms of decision quality. But the groups with GDSS reported more confidence with their decisions. Sharda et. al. [22] find that groups with DSS performed better than groups without the DSS aid, there was no difference between the two groups in terms of decision confidence. Sniezek \& Henry [26] note that groups are more confident in their decisions than individuals. Melone et. al. [17] find that DSS had no significant effect on confidence. In another study, Melone et.al. [17] conduct a 2x2 (DSS availability and decision environment) experimental design to assess issues related to performance and confidence. They found that DSS had an impact on performance. But subjects' confidence was not correlated with DSS availability. They also find a strong correlation between confidence and decision quality for all experimental conditions. Soll [25] hypothesizes that a major contributor to overconfidence is random error. The results of an empirical study show that most subjected reported accurately but with substantial random error.

Our research uses the induced-value controlled laboratory experimentation approach ([22], [23], [24]) to analyze the performance of individuals and of groups in decision making environments. In this approach, a performance based monetary reward system is used to induce optimal behavior from the participants. Smith emphasized the importance of such a reward mechanism to overcome possible subjective tendencies and to increase focus on full participation. Gardner, Marsden and Pingry [7] provide a detailed description of the key concepts and implications for laboratory experimentation. The use of performance-based rewards and information access charges can be directed at achieving meaningful subject performance and avoiding lack of interest, absenteeism, or subject dropouts [16]. We focus on the possibility of using monetary incentives (information costs and performance based reward 
mechanisms) to drive accurate user calibration. As true for any study of decision duality, our approach requires determination of a quality metric.

In order for users to be able to successfully pursue a profit maximizing process for themselves and for their firms, two conditions must be present. First, knowledge of all the relevant costs and benefits must exist, and, second, the performance based reward system present in a firm must incorporate all the relevant benefits and costs. It is possible that attitudes form due to a lack of knowledge about benefits and costs. We expect that no mismatch between perception and reality when the two above mentioned conditions exist. That is, there would not be any difference between perceived value and actual value. Our intent is to examine issues related to decision confidence and illusion of control in a group setting where subjects pay for information. We argue that illusion of control does not exist when subjects have information on costs and when they act in a profit maximizing behavior. Below, we detail the procedure that we used examine decision confidence and illusion of control in a group setting.

\section{METHODOLOGY}

\section{Task and Software}

In our experiment, the subjects act as commercial lending officers. They face the task of evaluating business loan applicants and deciding whether to approve a loan. They could grant a loan ranging from zero to the maximum amount requested. Loan officers usually make individual analysis, and then consult other fellow loan officers for extra input and or suggestions. To simulate the real life commercial lending process, we structured our experiments such that $a$ subject first makes an individual recommendation and then interacts with other loan officers to arrive at the group decision.

The software was designed in-house relying heavily on input from a local bank officer and from a banking professor colleague. In making a commercial lending decision, a loan officer relies on information from a variety of sources. These include credit reports, management capabilities, and financial records. We sought to develop a system that mimics the essential features of the commercial lending process within the confines of a laboratory. At the onset, information from the profit and loss statement (sales, earnings before income and tax, interest, earnings before tax, and earnings after tax), from the balance sheet (cash, other current assets, net fixed assets, total assets, short term debt, long term debt, stock, retained earnings, and total liability), and ratios (quick, current, debt to assets, asset turnover, earnings after tax to sales, earnings after tax to assets, earnings after tax to networth, coverage, and the $\mathrm{Z}$ score) were given.

The system provides both quantitative and qualitative support. Subjects could pay to access information on each of these elements. The quantitative support is provided through a mechanism for performing Whatif analysis. This is similar to a DSS or the use of spreadsheets to assess the impact of variation on a parameter such as profitability. Such a feature is extensively used in the financial sector. The system is capable of presenting financial performance statistics on the applicant firm if a loan of a particular amount is granted. When provided with What-if capabilities, subjects could also check the forecasted balance sheet and projected likelihood of loan repayment for any dollar amount between $\$ 1$ and the loan amount requested. The system can provide three different types of qualitative information on an applicant firm: a management capability rating (high, good, marginal, and bad), a rating on the status the applicant firm enjoys with the bank (good, average, fair, and new), and an economic outlook rating (good, average, and bad). The last of these provides a rating on the economy as it relates to the loan applicant firm, (i.e., the rating may be very good for a particular firm in a specific industry but fair or bad for a firm in another industry).

A subject can purchase information which represents information signals relating to the likelihood of default. Thus, if an applicant has good management, good economic outlook, god customer status, and a strong balance sheet, it is still possible for a loan default to occur. This outcome, however, is less likely than for a loan applicant with less favorable information signals. Each signal accessed by a subject results in a cost, an information charge. Performance outcomes relate to net outcomes or loan earnings minus information signal costs.

\section{Procedure}

The subject pool consisted of both students and bank personnel. The subjects participated in an earlier set of experiments where they acted as individual decision makers. A purpose of the individual set of experiments was to identify and select individuals who exhibited performance similar to the bank personnel. The group experiments involved subjects 
who had participated in individual experiments and performed at or above certain levels. The subject pool consists of sixteen students and two bank personnel. The student subjects were volunteers. The sixteen student subjects were assigned to groups of three (3) and five (5). The use of the bank personnel was to determine whether there are any differences in performance between the student population and real-world commercial loan decision makers. The use of subjects who participated in the individual set of experiments was to help ensure familiarity with the general decision-making process and to attempt to develop groups equal in member skills in the decision-making process (see [30], discussion of groups without prior system exposure failing to use the system in decision making).

Sessions lasting around 90 minutes were used to avoid subject fatigue. In a session for a group, there were a practice experiment (five decision periods), and two experiments (each with seven decision periods). In an experiment there were seven (7) decision periods. In a decision period, a subject first made a recommendation to the group. Then the group through electronic negotiation arrived at the group decision. The process was repeated for four (4) cycles. Thus there were a total of 56 individual recommendations $(2 * 7 * 4)$ and 56 group decisions.

There is a participation fee of $\$ 7$ and a performance based fee of up to $\$ 12$ per experiment. The subject has the potential to earn up to $\$ 19$. The best performance involved loaning the largest amount of money requested without incurring a default. A subject earns positive rewards as a percentage of repaid loans after deducting for all system usage (information) costs. There were three components to the performance based fee. One third was allocated by per decision period individual performance, another one third was allocated by per period group performance, and the final one-third was allocated by total performance (ending networth). Default determination was a realization of a random process set as a function of information on the applicant's current and projected balance sheet, management quality, sales forecasts, and economic outlook as it impacts the applicant firm. If a default occurred, a penalty was imposed. As suggested by the bank loan officer consultant, the penalty was set equal to twenty-five percent of the amount loaned. The lending officer indicated that this was consistent with net costs after collateral and loan security devices were taken into account.

\section{Measures}

Questionnaires were administered both prior to and after an experiment to elicit subjective responses. The dependent measures focuses on outcome of group decision making. Perception toward system usefulness formed the basis of subjective measurement. The measures for perception were elicited through use of a questionnaire. A five point scale (Strongly Disagree.. Disagree.. Uncertain.. Agree.. Strongly Agree) was used to elicit the responses to the following question: I find that I can predict a loan default situation accurately. The measures for task difficulty were elicited through use of a questionnaire. A five point scale (Strongly Disagree.. Disagree.. Uncertain.. Agree.. Strongly Agree) was used to elicit the responses to the following question: I find the task challenging. Performance (Ending networth) which was an objective measures was based on gross profit (loss). The gross profit is based on the amount granted and the prevailing interest rate. Gross loss is based on amount granted, and optimal loan amount.

\section{RESULTS}

In this section we present our results. A statistical analysis was performed using the statistical software package SPSS. The two groups are referred to as NDSS (GSS group without the What if capability) and YDSS (GSS group with the What if capability)

\section{Task Difficulty}

Task difficulty was assessed in terms of the subjects' responses to questionnaires administered both prior to and after an experimentation. A five point scale (Strongly Disagree.. Disagree.. Uncertain.. Agree.. Strongly Agree) was used to elicit the responses to the following question: I find the task challenging. The subjects reported that the task to be more difficult after completing the experiment (For NDSS, $\mathrm{Z}=-2.227, \mathrm{p}<0.05$; For YDSS, $\mathrm{Z}=-3.069, \mathrm{p}<$ 0.005 ; see table 1 for details). We also performed additional statistical analyses and found that there was no statistically significance difference between the two groups prior to the experiment (Mann Whitney $U=485.5 ; Z=-0.358 ; \mathrm{p}>0.05$ ). We also did not find any statistically significant difference between the two groups after the experiment (Mann Whitney $U=483 ; Z=-0.424 ; p>0.05)$. 
$<$ Insert Table 1 here

$>$

\section{Performance}

We use networth to assess performance. Networth related to the profit or loss associated with granting a loan. The use of a GDSS did not result in performance advantage (Mann Whitney $\mathrm{U}=6258.00$; $\mathrm{Z}=$ - 0.029; $\mathrm{p}>0.05$ ) (see also table 2).

here >

$<$ Insert Table 2

\section{Perception}

To examine perception, we use the responses to an item in the questionnaire which was stated as "Participants with what-if facilities perceive that when using a what-if facility they can determine when a loan default situation occurs. Analysis of the pre experiment survey (survey A, see table 3) shows that no significant difference exists (Mann Whitney $\mathrm{U}=441 ; \mathrm{Z}=-1.068 ; \mathrm{p}=>0.05$ ) between the two groups. But as a result of engaging in the experiment, significant changes in perception occurred for both NDSS (Wilcoxon signed text $\mathrm{Z}=$ 2.562; $\mathrm{p}=0.01$ ) and YDSS (Wilcoxon signed text $\mathrm{Z}$ $=-2.525 ; \mathrm{p}=0.012$ ).

here >

$<$ Insert Table 3

\section{DISCUSSION, SUMMARY REMARKS AND FUTURE RESEARCH DIRECTIONS}

This study is part of an ongoing project examining issues related to individual and group decision making using technologies. The purpose of this manuscript is to report on the results associated with group decision making. We find that in a challenging task, no difference in performance exists between subjects with and without a GDSS. Both groups (NDSS \& YDSS) report significant change in perception. Perception on the usefulness of the tool dropped as a result on engaging in the experimentation in an environment with performance based rewards. The subjects were accurately able to portray the capabilities of the GDSS. The use of market based experimentation environment (performance based rewards and system usage fees) resulted in illusion of control not being present and the participants could reconcile perception with reality.

Our findings have important implication for system designers and end users. We suggest that during system testing, end users may not be able to accurately portray the capabilities of the system as there is no direct relationship between their rewards and system capabilities. They may have inflated beliefs on the capabilities of the system. But, an organization has finite resources and a system that does not provide the intended capabilities results in wastage of resource.

We suggest the use of incentive mechanisms as a tool in the pursuit of perfect user calibration. Results of our initial experiments provide support for the potential use of reward mechanisms as the driver in achieving calibration. Given the growing use of increasing use of incentive based reward schemas in corporate America, our initial results support further, more detailed, study of the relationships between varying incentive mechanisms and calibration levels.

A key issue to be resolved by organizations is which tool-set will prove most effective in their setting. There will be organizations and settings in which incentive mechanisms will be relatively easy to structure and modify over time. In fact, prior research does offer some support for the use of rewards as a way of ensuring perfect calibration. Soll [25] noted that the weather forecasters are well calibrated and that the presence of historical data, guided forecasts, and large sample size may have contributed to this effect. He goes on to state:

Weather forecasters are evaluated and rewarded according to accuracy and calibration, a set of circumstances that might motivate them to reduce judgmental inconsistency. pp.134

Our results are based on a specific task using students as surrogates for managers. This may limit the generalizability of our results. To ensure greater validity, our subjects were chosen based on their performance in a similar task where they acted as individual decision makers. The performance of the subjects was compared to performance of commercial lending officers and only those subjects with comparable performance to the lending officers were chosen for the group study. Issues may also arise with the use of self reported measures for task difficulty and perception. 
There is a need for additional testing before our findings can be generalized across other domains. To date, our results are limited since we used only a single custom built system and dealt with only a single task. The results do encourage us to continue exploratory research expanding on both task and environment alternatives. As DSS and GDSS applications grow in flexibility and cost, it is increasingly important to develop design aids that increase the likelihood of system contribution. If individuals are to utilize a DSS/GDSS optimally, they must understand the system and be able to accurately calibrate system contribution to task performance.

Our research makes three contributions to the study of DSS/GDSS and organizational productivity. First, we present an easy to use and implement methodology to promote user involvement and achieve calibration. Second, we review relevant literature in the field of DSS/GDSS, decision confidence, judgment, and decision making, end user computing and present summarized findings. Finally, we identify additional research streams that need to be addressed by researchers if we are to reap the full benefits of DSS to the organizations.

\section{REFERENCES}

1. Arnott, D. (2006). Cognitive biases and decision support systems development: a design science Approach, Information Systems Journal, 16, 55 -78 .

2. Braun, P. A., \& Yaniv, I. (1992). A case study of expert judgment: Economists' probabilities versus base-rate model forecasts. Journal of Behavioral Decision Making, 5, 217-231.

3. Davis, F. D., \& Kottemann, J.E. (1994). User Perceptions of Decision Support Effectiveness: Two Production Planning Experiments. Decision Sciences, 25, 1, 57-78.

4. Davis, F. D., \& Kottemann, J.E. (1995). Determinants of Decision Rule Use in a Production Planning Task. Organizational Behavior and Human Decision Processes, 63, 2, 145-157.

5. Dunning, D., Griffin, D. W., Milojkovic, J. D., \& Ross, L. (1990). The overconfidence effect in social prediction. Journal of Personality and Social Psychology, 58, 568-581.
6. Duhaime, I.M., \& Schwenk, C.R. (1985). Conjectures on Cognitive Simplification in Acquisition and Divestment Decision Making, The Academy of Management Review, 10 (2), pp. 287-295

7. C. Gardner, J.R. Marsden, and D.E. Pingry, "DSS Evaluation: A Comparison of Ex-ante and Ex-post evaluation methods," Decision Support Systems: Theory and application, Italy, NATO Advanced Study Institute, pp. 16-28, 1991.

8. Grady, R. B. (1995). Successfully Applying Software Metrics, Communications of the ACM, 38(3), 18- 25.

9. Johnson, E. J. (1988). Expertise and Decision Under Uncertainty: Performance and Process. In M. T. H. Chi, R. Glaser, \& M. J. Farr (Eds.), The Nature of Expertise (pp. 209-228). Hillsdale, NJ: Lawrence Erlbaum Associates.

10. Kasper, G. M (1996). A Theory of Decision Support System Design for User Calibration. Information Systems Research, 7, 2, 215-232.

11. Keren, G. (1991). Calibration and Probability Judgments: Conceptual and Methodological Issues. Acta Psychologica, 77, 217-273.

12. Kottemann, J. E., Davis, F.D., \& W. E Remus. (1994). Computer-Assisted Decision Making: Performance, Beliefs, and the Illusion of Control. Organizational Behavior and Human Decision Processes. 57, 1, 26-37.

13. Koriat, A., Lichtenstein, S., \& Fishchhoff, B. (1980). Reasons for Confidence. Journal of experimental Psychology: Human Learning and Memory, 6, 107 - 118.

14. Langer, E. J. (1983). The Psychology of Control,. Beverly Hills, CA: Sage Publications.

15. Lichtenstein, S., Fischhoff, B., \& Phillips, L. (1982). Calibration of Probabilities State of the Art to 1980. In D. Kahneman, P. Slovlc, \& A Tversky (Eds ), Judgment Under Uncertainty: Heuristics and Biases. Cambridge, England: Cambridge University Press.

16. Marsden, J. R., \& Mathiyalakan, S. (1997). An empirical investigation into the relationship between performance and perception of users with a what-if facility. Journal of Organizational 
Computing and Electronic Commerce. 7, 4, 305326.

17. Melone, N.P., McGuire, T. W., Hinson, G.B., \& Yee, K.Y. (1993). The Effect of Decision Support Systems on Managerial Performance and Decision Confidence. In J.F. Nunamaker, Jr. \& R.H. Sprague, Jr. (Eds.). Proceedings of the Twenty-Sixth Annual Hawaii International Conference on System Science. Vol. IV, Los Alamitos, CA: IEEE Computer Society Press, pp. 482-489.

18. Morris, S.A., \& Marshall, T.E. (2004). Perceived Control in Information Systems. Journal of Organizational and End User Computing. 16,2, 38-56.

19. Panko, Raymond R. (2006). Spreadsheets and Sarbanes-Oxley: Regulations, Risks, and Control Frameworks, Communications of the AIS, 17(9).

20. Plous, S. (1993). The Psychology of Judgment and Decision Making. Philadelphia: Temple University Press.

21. Sharda, R, Barr, S.H., \& McDonnell, J.C. (1988). Decision Support System Effectiveness A Review and an Empirical Test. Management Science, 34, 2, 139-159

22. Smith, V. L. (1976). Experimental Economics: Induced Value Theory. American Economic Review. 66, 2, 274-279.

23. Smith, V. L. (1982). Microeconomic Systems as Experimental Science. American Economic Review, 72, 5, 923-955.

24. Smith, V. L. (1985). Experimental Methods in Economics. In J. M. Eatwell, M. Milgate \& P. Newman (Eds.), The New Palgrave: A Dictionary of Economic Theory and Doctrine. New York, NY: Macmillan Press Ltd.

25. Soll, J. B. (1996). Determinants of Overconfidence and Mis-calibration: The Roles of Random Error and Ecological Structure. Organizational Behavior and Human Decision Processes. 65, 2, 117-137.

26. Sniezek, J. A. \& Henry, R.A. (1989). Accuracy and Confidence in Group Judgment. Organizational Behavior and Human Decision Processes, 43,l, 1-28.
27. Steeb, R. \& Johnston, S.C. (1981). A ComputerBased Interactive System for Group Decision making, IEEE Trans. Systems, Man, and Cybernetics 11, 8, 544-552.

28. Wagenaar, W.A. (1988) Paradoxes of Gambling Behaviour. Lawrence Erlbaum, East Sussex, UK.

29. Yates, J F. (1990). Subjective Probability Accuracy Analysis. In Wright, G. \& P. Ayton (Eds.), Subjective Probabrlity, New York: Wiley.

30. Zigurs, I., Poole, M.S., DeSanctis, G. (1988). A Study of Influence in Computer-Mediated Group Decision Making. MIS Quarterly. 12, 4, 625644.

\begin{tabular}{l|cc}
\hline & NDSS & YDSS \\
\hline Survey A (Pre)- & $3.41(1.1$ & 3.25 \\
Mean (SD) & $0)$ & $(1.34)$ \\
Survey B (Post) & 3.88 & 3.94 \\
- Mean (SD) & $(0.94)$ & $(0.95)$ \\
& & \\
Wilcoxon Signed & $\mathrm{Z}=$ & $\mathrm{Z}=-$ \\
Test & 2.227 & 3.069 \\
& $\mathrm{P}$ & $\mathrm{P}$ \\
& 0.026 & 0.002 \\
\hline $\mathbf{N = \mathbf { 2 8 }}$ \\
\hline
\end{tabular}

Table 1: Statistics for Task Difficulty

\begin{tabular}{l|cc}
\hline DSS & NDSS & YDSS \\
\hline End Networth & $174.25(200.03)$ & 130.81 \\
(\$) & \multicolumn{2}{|c}{$(270.24)$} \\
Mann Whitney & \multicolumn{2}{|c}{6258.00} \\
U & $\mathrm{Z}=-0.029 ; \mathrm{P}>0.05$ \\
\hline $\mathbf{2}=\mathbf{2 8}$
\end{tabular}

Table 2: Statistics for Performance

\begin{tabular}{l|ll}
\hline & NDSS & YDSS \\
\hline $\begin{array}{l}\text { Survey A-Mean } \\
\text { (SD) }\end{array}$ & $3.69(0.93)$ & $3.47(1.01)$ \\
$\begin{array}{l}\text { Survey B - Mean } \\
\text { (SD) }\end{array}$ & $3.25(0.84)$ & $2.97(0.93)$ \\
$\begin{array}{ll}\text { Wilcoxon Signed } \\
\text { Test }\end{array}$ & $\mathrm{Z}=-2.562$ & $\mathrm{Z}=-2.525$ \\
\hline $\mathbf{N = \mathbf { 2 8 }}$ & $\mathrm{P}=0.01$ & $\mathrm{P}=0.012$ \\
\hline
\end{tabular}

Table 3: Statistics for Perception 